\title{
Atitudes dos Alunos dos Cursos de Ciências Sociais Aplicadas em Relação à Estatística
}

\author{
Daielly Melina Nassif Mantovani ${ }^{1}$ \\ Maria Flávia Barbosa Leite ${ }^{2}$ \\ Guilherme de Farias Shiraishi ${ }^{3}$ \\ Adriana Backx Noronha Viana ${ }^{4}$
}

\section{Resumo}

O objetivo deste trabalho é identificar o perfil de atitudes de alunos de cursos de Ciências Sociais Aplicadas em relação à Estatística. Trata-se do resultado obtido através da aplicação de um questionário, a escala SATS (Survey of Attitudes Toward Statistics), a 337 alunos de cursos de Administração e Contabilidade de duas faculdades da região de Ribeirão Preto. Obteve-se, pela análise fatorial, duas dimensões atitudinais, denominadas valor e competência cognitiva e dificuldade. Pela análise de cluster foram obtidos quatro grupos de alunos, um com atitude predominantemente positiva, dois com atitude indefinida e um com atitude negativa. Foram aplicados os testes Mann-Whitney e Kruskal-Wallis para verificar a existência de diferença atitudinal entre os clusters, entre os cursos e entre os sexos masculino e feminino. Observou-se que os alunos possuem sentimentos positivos em relação à Estatística, mas consideram-na complexa e sentem insegurança quanto à aprendizagem dos conceitos e ferramentas estatísticos.

Palavras-chave: Atitudes. Avaliação Educacional. Estatística Aplicada.

\section{Introdução}

Os cursos de graduação, em sua maioria, possuem disciplinas de Estatística na grade curricular. Os conteúdos ministrados nessas disciplinas, apesar de serem teóricos, costumam ser a base para a aprendizagem de outras

\footnotetext{
${ }^{1}$ Doutoranda em Administração pela FEA/USP. Faculdade de Economia, Administração e Contabilidade de Ribeirão Preto FEA-RP/USP. Endereço: Av: do Rio Pequeno, 120, ap. 131 - I, CEP: 05379-000, São Paulo-SP - Brasil. Email: daimantovani@terram.com.br.

${ }^{2}$ Bacharel em Administração pela FEA-RP/USP. Faculdade de Economia, Administração e Contabilidade de Ribeirão Preto FEA-RP/USP. Endereço: Rua Prudente de Morais 448, ap. 43 CEP: 14015-100, Ribeirão Preto - SP - Brasil. E-mail: mariaflavia_leite@yahoo.com.br.

${ }^{3}$ Doutorando em Administração pela FEA/USP. Professor Universidade Mackenzie. Endereço: Av: do Rio Pequeno, 120, ap. 131 - I, CEP: 05379000, São Paulo-SP - Brasil. E-mail: guilhermefs@gmail.com.

${ }^{4}$ Professora Doutora Livre Docente do Departamento de Administração da FEA-RP/USP. Endereço: Av. dos Bandeirantes 3900, Campus USP, FEA-RP, Sala 70, CEP:14040-900. Email: backx@usp.br. Artigo recebido em: 17/10/2006. Aceito em: 23/05/2007. Membro do Corpo Editorial Científico responsável pelo processo editorial: Gilberto de Oliveira Moritz.
} 
disciplinas mais específicas do curso. No entanto, dificuldades eminentes de aprendizado existem no ensino da Estatística, especialmente para alunos de cursos de ciências aplicadas, tais como Administração e Contabilidade, em que a estatística é uma ferramenta de apoio à tomada de decisões (PETOCZ; REID, 2005).

Essas dificuldades se referem à percepção de complexidade que os alunos associam à Estatística. Alunos de cursos de ciências sociais aplicadas mostram-se resistentes à disciplina por julgarem-na muito complicada, devido ao volume de cálculos e fórmulas envolvidos, e por não conseguirem fazer uma ligação entre os conhecimentos estatísticos e sua aplicação em questões práticas (NOLAN; SPEED, 1999).

Muitos estudantes destes cursos não possuem uma base adequada de conhecimentos matemáticos e estatísticos, de forma que acabam por vivenciar alto grau de ansiedade durante os cursos de estatística (PAN; TANG, 2004). A ansiedade estatística pode afetar negativamente a aprendizagem do aluno e é definida como a ansiedade enfrentada como resultado de se deparar com a estatística de qualquer forma e em qualquer nível (PAN; TANG, 2004).

As atitudes exercem forte influência no processo de ensino-aprendizagem de estatística, pois contribuem para a forma de comportamento do aluno na disciplina de estatística $e$ afetam a extensão à qual o estudante desenvolverá o pensamento estatístico e será capaz de aplicar os conceitos aprendidos fora do ambiente escolar (SUAPANG; PETOCZ, KALCEFF, 2003).

Paralelamente, existe o fator agravante de que os professores que ministram disciplinas de estatística nos cursos de Administração e Contabilidade costumam possuir formação matemática e recebem pouca preparação para a questão didática, o que os leva a ter dificuldades em aproximar a estatística do contexto real dos alunos não-estatísticos (GELMAN, 2005).

Como resultado da interação de todos os fatores já apresentados, temse uma influência negativa na aprendizagem e a estatística se torna uma das competências mais fracas adquiridas durante a universidade (PAN; TANG, 2004).

Frente ao contexto apresentado, torna-se necessário conhecer as atitudes dos alunos em relação à Estatística, pois no âmbito educacional, as atitudes positivas podem determinar interesse pelo estudo das disciplinas e atitudes negativas podem revelar dificuldades de aprendizagem. Além disso, o conhecimento do perfil de atitudes é importante para que os educadores possam delinear novas estratégias de ensino mais ajustadas à sua clientela 
(CARZOLA et al., 1999), que auxiliem no desenvolvimento de atitudes positivas ou na modificação de atitudes negativas em relação à Estatística (SILVA et al., 2002).

O objetivo deste trabalho é estudar a atitude de alunos dos cursos de Administração e Contabilidade de duas instituições de ensino superior, da região de Ribeirão Preto, em relação à Estatística, verificando a existência de diferenças significativas entre grupos de alunos, encontrados pela análise de cluster, entre os cursos e entre os sexos: masculino e feminino. Para tal propósito, aplicou-se um questionário, a escala para mensuração de atitudes denominada SATS (Survey of Attitudes Toward Statistics).

A seguir, será apresentada a fundamentação teórica, a metodologia do trabalho, a análise dos dados obtidos e as conclusões do estudo.

\section{Fundamentação Teórica}

\subsection{Atitudes}

Não existe consenso na literatura sobre o conceito de "atitudes" (CARZOLA et al., 1999). A palavra deriva do latim "aptus", tendo assumido significado inicial de "aptidão" ou "adaptação", com o sentido de capacidade física. Com o passar do tempo, o termo passou a ser empregado também com o sentido de "preparação mental" (GONÇALVES, 2002).

Devido à amplitude do termo, existe uma larga gama de definições na literatura. Menezes (1986 apud GONÇALVES, 2002, p. 54) cita algumas definições:

[...] postura mental; disposição mental específica em relação a uma experiência que está para se realizar; complexo de sentimentos, receios, desejos, convicções e prevenções; disposição mental do indivíduo humano para agir contra ou a favor de algum objeto definido; meio emocional de se considerar objetos; gostos ou antipatias, afinidades e aversões; orientação de aproximação ou afastamento em relação a um objeto. 
Mostra-se mais adequada ao propósito deste estudo a definição de atitude como sendo a predisposição à ação contra ou a favor de um objeto, a estatística (BRESSAN, 1995). Essa definição apresenta um aspecto afetivo, considerando as crenças do indivíduo em relação à estatística. Haverá uma predisposição a favor da estatística se o aluno apresentar crenças favoráveis e tiver experimentado situações agradáveis envolvendo a estatística. Da mesma forma, haverá predisposição contra a estatística se o aluno apresentar crenças desfavoráveis e tiver experimentado situações de alto estresse envolvendo a estatística, tanto no âmbito educacional quanto no cotidiano.

As atitudes se fundamentam em quatro atividades humanas: pensar, sentir, comportar-se e interagir com outros, isto é, possui componentes cognitivos, emocionais, comportamentais e sociais (BEM, 1973).

Para Bressan (1995), entende-se por afeto os valores e sentimentos do indivíduo em relação ao objeto. A cognição é considerada como o conhecimento, as opiniões, as crenças e os pensamentos associados ao objeto. $\mathrm{O}$ comportamento envolve as intenções, interações e ações sobre o objeto. O modelo a seguir expõe a estrutura conceitual da atitude (Figura 1).

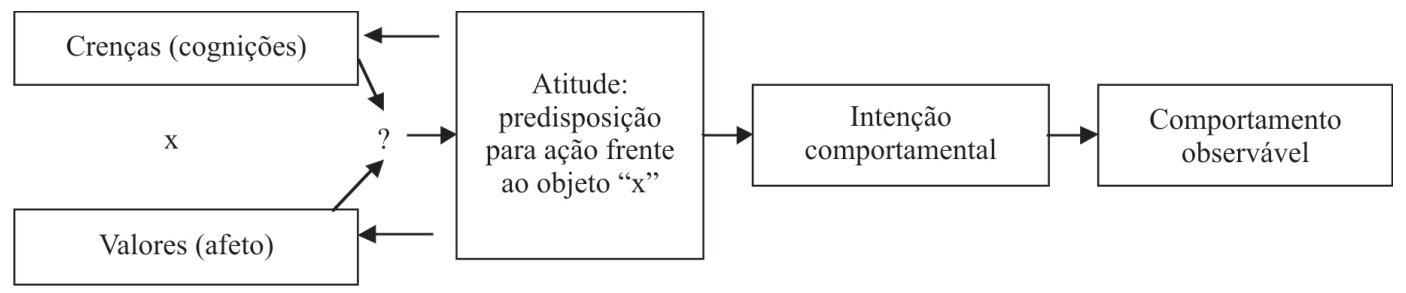

Figura 1: Representação esquemática da estrutura conceitual da atitude. Fonte: Bressan (1995, p. 54).

Para Bressan (1995), a atitude em relação ao objeto é a somatória das crenças (componente cognitivo) sobre o objeto, adquiridas através de aprendizagem e dos valores (componente afetivo) atribuídos às crenças e associados aos atributos do objeto. Dessa forma, entendendo a atitude como uma disposição para a ação, é possível concebê-la apenas como um fenômeno afetivo/cognitivo.

Essa organização de crenças e cognições dotada de carga afetiva leva o indivíduo a ter comportamento e ação específicos diante de determinado 
objeto, ou seja, a atitude do sujeito em relação ao objeto permite predizer os comportamentos e ações que ele terá em situações que envolvem o referido objeto (TRONCON et al., 2003).

No âmbito educacional as atitudes dos alunos em relação aos "objetos" são relevantes, considerando a relação existente entre atitudes e aprendizagem (TRONCON et al., 2003). A motivação é maior quando os estudantes se deparam com conceitos aos quais são favoráveis. Por outro lado, atitudes negativas em relação aos conceitos podem acarretar em dificuldades de aprendizagem.

\subsection{Atitudes em Estatística}

A importância das aplicações da estatística como ferramenta de auxílio à tomada de decisões tem crescido nos últimos anos e com isso surge a necessidade de compreender as dificuldades no ensino desta disciplina. De acordo com Gal e Ginsburg (1994), a estatística é considerada um obstáculo que se opõe ao alcance de objetivos dos universitários. Os estudantes, em geral, recordam-se da tensão pela qual passaram durante o curso de estatística, mas os conteúdos ensinados são esquecidos por grande parte dos alunos (GAL; GINSBURG, 1994).

Muitas dessas dificuldades podem ser explicadas pela atitude dos universitários em relação à Estatística. A atitude desfavorável pode estar relacionada a experiências desagradáveis vivenciadas em situações envolvendo a estatística ou pela associação feita por alguns alunos entre a estatística e a matemática. Segundo Gal, Ginsburg e Schau (1997), quando o aluno considera a estatística como um ramo da matemática, transfere para a estatística sua atitude em relação à matemática, que em cursos de ciências aplicadas costuma ser negativa. Por conseguinte, os alunos enfrentam certa ansiedade ao cursar disciplinas de estatística, frequentemente, iniciando o curso já com atitudes negativas (CARZOLA et al., 1999). Destaca-se que a atitude favorável em relação à estatística pode aproximar o aluno da disciplina, estimulando-o a ampliar seus conhecimentos ou a utilizar os conceitos aprendidos (SILVA et al., 2002). Ademais, quanto mais favorável a atitude, melhor é o desempenho na disciplina (SILVA; CARZOLA; BRITO, 1999).

É de extrema relevância conhecer a atitude dos alunos em relação à Estatística, por três razões: 1 ) influência dos aspectos atitudinais no ensinoaprendizagem; 2) influência no comportamento estatístico dos alunos fora 
das aulas; e 3) influência na decisão dos alunos em participar de outros cursos de Estatística no futuro (GAL; GINSBURG; SCHAU, 1997). Assim, as instituições de ensino e professores passam a conhecer os sentimentos e predisposições dos alunos, o que permite o desenvolvimento de novas estratégias de ensino que tornem o estudo da estatística mais interessante aos alunos (CARZOLA et al., 1999). Desta forma, pode-se proporcionar aprendizagem efetiva dos conceitos e ferramentas e capacitar os alunos na utilização adequada e consistente da estatística, tanto no ambiente acadêmico quanto profissional, tendo em vista que os alunos são não-estatísticos, então usuários da estatística.

Alguns estudos empíricos sobre o tema encontrados na literatura, apesar de não utilizarem a mesma escala de atitudes aplicada neste trabalho, oferecem insights ao presente estudo, pois permitem criar algumas hipóteses a respeito da existência de diferença significativa de atitudes entre categorias de alunos.

O estudo de Carzola et al. (1999) tiveram como objetivo validar uma escala de atitudes em relação à estatística e aplicou tal escala em alunos de quinze cursos de graduação de duas universidades paulistas, uma localizada na capital e outra do interior do estado. Foi constatada uma diferença significativa de atitudes entre as duas universidades estudadas, sendo que a universidade localizada no interior do estado apresentou atitude mais positiva do que a atitude da universidade sediada na capital. Os testes de hipóteses não mostraram diferença significativa de atitude entre os gêneros. Contudo, comparando as atitudes entre as áreas, o estudo de Carzola et al. (1999) verificou que os alunos dos cursos de humanas apresentam atitudes mais negativas do que os alunos de cursos da área de exatas e ciências da saúde.

Silva et al. (2002) estudaram atitudes de alunos de cursos universitários em relação à estatística e à matemática e verificaram a existência de relacionamento entre os dois tipos de atitudes. Dos alunos estudados, mais da metade apresentou atitudes positivas em relação à estatística. Analogamente ao estudo de Carzola et al. (1999), Silva et al. (2002) não identificaram diferença significativa de atitudes em relação à estatística entre o sexo feminino e masculino. Todavia, foi identificado que os alunos dos cursos de humanas apresentaram atitudes mais negativas do que os alunos dos cursos de exatas e ciências da saúde.

Silva, Carzola e Brito (1999) aplicaram uma escala de atitudes em relação à estatística em alunos de diversos cursos que pertenciam ao programa 
de iniciação científica de uma instituição de ensino superior. As autoras constaram que os alunos do sexo masculino possuem atitudes mais positivas do que as alunas do sexo feminino, assim como os alunos da área de exatas apresentaram atitudes mais positivas do que os alunos dos cursos de humanas, saúde e comunicação. Adicionalmente, constataram que os alunos que já haviam aplicado conceitos estatísticos em seus estudos possuíam atitudes mais positivas do que os alunos que nunca a haviam utilizado. Da mesma forma, os alunos que declararam considerar a estatística como uma ferramenta muito importante apresentaram atitudes mais favoráveis do que os alunos que a consideraram menos importante.

Como afirma Pedrão, Avanci e Malaguti (2002), as atitudes são aprendidas e, assim, passíveis de mudança. Portanto, tendo conhecimento sobre a atitude dos estudantes é possível agir, modificando a forma de ensino e incluindo estratégias inovadoras, de forma a transformar a atitude desfavorável em favorável. Dessa forma, o comportamento de resistência em relação à Estatística, determinado pela atitude negativa, pode ser reduzido e até transformado em uma experiência agradável para o aluno.

\section{Método}

\subsection{Abordagem da Pesquisa}

Com base na classificação de Gil (2002, p. 42-43), o presente estudo, em relação ao seu objetivo geral, é classificado como uma pesquisa descritiva.

As pesquisas descritivas têm como objetivo primordial a descrição das características de determinada população ou fenômeno ou, então, o estabelecimento de relações entre variáveis. São inúmeros os estudos que podem ser classificados sob esse título e uma de suas características mais significativas está na utilização de técnicas padronizadas de coleta de dados, tais como o questionário e a observação sistemática.

A presente pesquisa possui como objetivo analisar a atitude dos alunos dos cursos de ciências sociais aplicadas (Administração e Contabilidade) 
perante a Estatística, através de uma coleta estruturada e de análise estatística dos dados. Adicionalmente, analisou-se a existência de diferença significativa de atitudes entre os cursos, o gênero e os clusters identificados por meio de testes de hipóteses.

\subsection{Metodologia de Análise dos Dados}

Para atingir os objetivos do estudo, foram aplicadas análises estatísticas multivariadas (Análise fatorial de componentes principais e Análise de cluster) e testes de hipóteses não-paramétricos (Kruskal-Wallis e Mann-Whitney), que serão definidos a seguir.

\subsection{Análise dos componentes principais}

A análise fatorial de componentes principais consiste de uma gama de métodos estatísticos multivariados, cujo objetivo é encontrar uma estrutura latente em uma matriz de dados (HAIR et al., 1998). Segundo Pasquali (1997, p. 57), o conceito de estrutura latente apresenta controvérsias entre os estudiosos do assunto. $\mathrm{Na}$ concepção da análise fatorial, a estrutura latente é definida como grandes estruturas que variam de sujeito para sujeito e:

[...] os fatores são concebidos como variáveis fonte responsáveis pela qualidade da execução de tarefas comportamentais [...] apresentam ainda um caráter globalizante, dado que não expressam processos cognitivos elementares, mas sim um possível conjunto destes que são necessários para execução de uma tarefa concreta.

A análise fatorial dos componentes principais permite transformar um conjunto de variáveis iniciais, correlacionadas entre si, em um conjunto de variáveis não correlacionadas, que mantém características do conjunto inicial (REIS, 2001). As componentes principais são calculadas por ordem de importância, sendo que a primeira componente, ou primeiro fator, explica o máximo possível da variância dos dados originais, o segundo fator explica o máximo possível da variância ainda não explicada, etc. (REIS, 2001).

Essa análise se difere de outros tipos de análise fatorial, pois seu objetivo é encontrar funções matemáticas lineares entre as variáveis iniciais que 
expliquem o máximo possível da variação existente nos dados. Não impõe uma relação de causalidade entre as variáveis, assim, considera apenas a variação total existente no conjunto original de variáveis, não trabalhando com a variação comum partilhada pelas variáveis (REIS, 2001).

As amostras devem possuir no mínimo 50 observações, mas, em geral, a quantidade de observações deve ser cinco vezes maior do que a quantidade de variáveis, para que a aplicação do modelo seja satisfatória (HAIR et al., 1998). A adequação do modelo é verificada por meio do Teste de esfericidade de Bartlett e da Medida de Adequação da Amostra. O teste de Bartlett verifica a probabilidade de que a matriz de correlação seja uma matriz identidade, com determinante igual a um, o que indica que as variáveis não estão correlacionadas entre si. Trata-se de um teste de hipóteses, cuja hipótese nula afirma que a matriz de correlações da população é uma matriz identidade e as variáveis não possuem correlação significativa entre si. Para que o modelo de análise fatorial dos componentes principais possa ser aplicado, deve-se rejeitar a hipótese nula, pois é necessário algum grau de correlação entre as variáveis para que os fatores possam ser extraídos (REIS, 2001; HAIR et al., 1998).

De forma complementar, a medida de adequação da amostra (estatística de Kaiser-Meyer-Olkin - KMO) compara as correlações entre as variáveis, considerando as correlações observadas entre as variáveis e o coeficiente parcial de correlação entre elas, resultando em um coeficiente de adequação do modelo (REIS, 2001). Esse valor pode variar entre zero e um (REIS, 2001; HAIR et al., 1998), devendo ser interpretado segundo o Quadro 1 (REIS, 2001, p. 279):

\begin{tabular}{|c|c|}
\hline KMO & Análise dos Componentes Principais \\
\hline Entre 1 e 0,9 & Muito boa \\
\hline Entre 0,8 e 0,9 & Boa \\
\hline Entre 0,7 e 0,8 & Média \\
\hline Entre 0,6 e 0,7 & Razoável \\
\hline Entre 0,5 e 0,6 & Má \\
\hline Menor que 0,5 & Inaceitável \\
\hline
\end{tabular}

Quadro 1: Interpretação do coeficiente KMO.

Fonte: Reis (2001, p. 279). 
A rotação de fatores é um procedimento utilizado para facilitar a interpretação desses fatores, à medida que transforma os coeficientes do modelo em uma estrutura simplificada com fatores tão independentes entre si quanto possível (REIS, 2001). Há dois métodos de rotação: ortogonal e oblíquo. O método ortogonal pressupõe independência entre os fatores e os rotaciona mantendo um ângulo reto entre eles. Em oposição, o método oblíquo, denominado Oblimin, não pressupõe independência entre as componentes, permitindo-lhes uma rotação livre, de forma a simplificar o agrupamento das variáveis e a interpretação dos fatores (REIS, 2001).

O método mais popular é a rotação ortogonal varimax, proposta por Kaiser em 1958 (REIS, 2001). Esse método busca simplificar as colunas (que representam os fatores) da matriz de fatores de forma que haja apenas valores zero ou próximos de um, ou seja, seu objetivo é maximizar a variação entre os pesos de cada fator (REIS, 2001; HAIR et al., 1998).

Há outros métodos de rotação ortogonal: quartimax e equimax. O método quartimax procura, por meio da simplificação das linhas de uma matriz de pesos, transformar os pesos de algumas variáveis em valores elevados para alguns fatores e simultaneamente em valores próximos de zero nos outros fatores (REIS, 2001; HAIR et al., 1998). Por fim, o método equimax pode ser considerado como um intermediário entre os métodos varimax e quartimax, pois simplifica simultaneamente as linhas e colunas da matriz de pesos (REIS, 2001; HAIR et al., 1998).

Neste trabalho aplicou-se a análise fatorial dos componentes principais com rotação ortogonal varimax. Esse método rotacional foi selecionado, porque pressupõe a independência entre os fatores obtidos, ou seja, os fatores resultantes não são altamente correlacionados. Essa é uma característica desejável, à medida que se aplicou uma análise de cluster sobre os fatores encontrados.

\subsubsection{Análise de cluster}

A análise de cluster é um grupo de técnicas multivariadas cujo objetivo é agrupar objetos com base em suas características comuns (HAIR et al., 1998). O método teve sua origem na biologia com a obra de Sokal e Sneath de 1963, que propôs a classificação biológica pela análise de cluster, em que organismos semelhantes seriam agrupados em um mesmo grupo, baseandose nas informações existentes sobre eles (REIS, 2001). 
Os grupos obtidos são denominados clusters e possuem alta homogeneidade interna e alta heterogeneidade externa. Dessa forma, os casos dentro de um grupo são parecidos, mas diferentes dos casos de outros clusters (HAIR et al., 1998). As variáveis são interdependentes, ou seja, os grupos são definidos sem estabelecerem uma relação de causalidade entre as variáveis (REIS, 2001).

Tal ferramenta coloca as observações mais similares dentro de grupos e para poder classificá-las como tais é necessário escolher uma medida de semelhança. No caso da análise de clusters, a semelhança entre os casos pode ser constatada através de: medidas de correlação, medidas de distância espacial e medidas de associação. As medidas de distância são mais comumente utilizadas, pois os objetos mais próximos são mais semelhantes entre si do que os objetos mais distantes (HAIR et al., 1998). As medidas de distância mais comumente utilizadas são a distância euclidiana simples (Distância Euclideana $=\sqrt{\left(x_{2}-x_{1}\right)^{2}+\left(y_{2}-y_{1}\right)^{2}}$ onde (x,y) são as coordenadas espaciais dos pontos considerados) ou a distância euclidiana absoluta (Distância Euclideana Absoluta $\left.=\left(x_{2}-x_{1}\right)^{2}+\left(y_{2}-y_{1}\right)^{2}\right)$ por meio de um procedimento hierárquico ou não- hierárquico. $\mathrm{O}$ método hierárquico aglomerativo (aplicado neste estudo) trabalha agrupando casos até que todos os casos da amostra formem um único grande cluster (HAIR et al., 1998). $\mathrm{O}$ agrupamento é realizado por meio de um algoritmo de aglomeração. Nesse trabalho utilizou-se o método de Ward como algoritmo de aglomeração. Nesse método, a medida de similaridade utilizada para o agrupamento é obtida pelo somatório dos quadrados entre dois clusters, para todas as variáveis. O método tende a obter clusters de mesmo tamanho, pois minimiza a variância dentro dos grupos (HAIR et al., 1998).

\subsubsection{Teste de Mann-Whitney}

O teste Mann-Whitney (conhecido como teste U) é utilizado para testar se dois grupos independentes foram extraídos da mesma população. Tratase de um dos mais poderosos testes não-paramétricos, utilizado para escalas ordinais ou quando os pressupostos dos testes paramétricos não são preenchidos (SIEGEL; CASTELLAN JR., 2006). As hipóteses do teste podem ser estabelecidas em termos da mediana ( ) dos dados, tendo em vista a impossibilidade de calcular a média para dados ordinais. Nesse contexto, as hipóteses para o teste entre dois grupos "a" e "b" seriam: 


$$
\begin{aligned}
& H_{0}: \theta_{a}=\theta_{b} \\
& H_{1}: \theta_{a} \neq \theta_{b} \text { ou } \theta_{a}>\theta_{b} \text { ou } \theta_{a}<\theta_{b}
\end{aligned}
$$

Tem-se que $\theta_{a}, \theta_{b}$ são as medianas para o grupo " $a$ " $e$ " $b$ " respectivamente.

O teste é aplicado da seguinte maneira: as observações combinadas $\left(n_{\mathrm{a}}+n_{\mathrm{b}}\right)$ são ordenadas de forma crescente e os postos são atribuídos (os maiores valores negativos recebem os menores postos e assim sucessivamente até que o maior valor positivo receba o maior posto). A estatística U é obtida, então, pelas fórmulas 3 e 4 (SIEGEL, 1975).

$$
U=n_{a} n_{b}+\frac{n_{a}\left(n_{a}+1\right)}{2}-R_{a} \text { (3) ou } U=n_{a} n_{b}+\frac{n_{b}\left(n_{b}+1\right)}{2}-R_{b} \text { (4) onde } n_{a}
$$

representa o número de observações no grupo " $\mathrm{a}$ "; $n_{\mathrm{b}}=$ número de observações no grupo "b"; $R_{\mathrm{a}}=$ soma dos postos atribuídos ao grupo cujo tamanho é $n_{\mathrm{a}} ; R_{\mathrm{b}}=$ soma dos postos atribuídos ao grupo cujo tamanho é $n_{\mathrm{b}}$.

As fórmulas 3 e 4 podem apresentar resultados diferentes, devendo-se escolher o menor valor obtido. A significância, para grandes amostras $\left(n_{\mathrm{b}}>20\right.$ onde o grupo "b" é o maior grupo) pode ser testada pela equação 5 (SIEGEL, 1975).

$$
z=\frac{U-\mu_{U}}{\sigma_{U}}(5) \text { onde } \mu_{U}=\frac{n_{a} n_{b}}{2}(6) \text { e } \sigma_{U}=\sqrt{\frac{\left(n_{a}\right)\left(n_{b}\right)\left(n_{a}+n_{b}+1\right)}{12}}(7)
$$

\subsubsection{Teste de Kruskal-Wallis}

O teste Kruskal-Wallis é aplicado para verificar se $\mathrm{k}$ amostras independentes provêm de populações iguais ou com a mesma mediana (SIEGEL; CASTELLAN JR., 2006). Dessa forma, "o teste admite que as variáveis sob estudo têm a mesma distribuição contínua subjacente; assim, ele requer pelo menos mensuração ordinal da variável" (SIEGEL; CASTELLAN JR., 2006, p. 235). As hipóteses para este teste são:

$H_{0}: \theta_{1}=\theta_{2}=\theta_{3}$ (as medianas das populações são iguais)

$H_{1}$ : pelo menos um par de grupos possui medianas diferentes

Tem-se que $\theta_{1}, \theta_{2}, \theta_{3}$ são as medianas para o grupo 1,2 e 3 respectivamente. 
Primeiramente, para a aplicação do teste, os dados são colocados em uma matriz onde cada grupo representa uma coluna e cada linha representa uma observação. Na sequência, atribuem-se postos aos escores combinados (organizados em uma única série). O menor escore recebe o posto 1 e assim sucessivamente até que o maior escore receba o posto mais elevado. Calcula-se então a soma dos postos para cada grupo (coluna da matriz) e retira-se uma média. Se os grupos provêm de populações iguais ou com a mesma mediana, os postos médios devem ser parecidos (SIEGEL; CASTELLAN JR., 2006). Por fim, para o teste da significância, utilizam-se as fórmulas 8 e 9 (SIEGEL; CASTELLAN JR., 2006).

$$
K W=\frac{12}{N(N+1)} \sum_{j=1}^{k} n_{j}\left(\overline{R_{j}}-\bar{R}\right)^{2}(8) \text { ou } K W=\left[\frac{12}{N(N+1)} \sum_{j=1}^{k} n_{j} \overline{R_{j}^{2}}\right]-3(N+1)(9)
$$

onde $\mathrm{k}=$ número de grupos ou amostras; $n_{\mathrm{j}}=$ número de casos na j-ésima amostra; $\mathrm{N}=$ número de casos na amostra combinada (soma dos $n_{j}$ ); $\overline{R_{j}}=$ média dos postos na j-ésima amostra/grupo; $\bar{R}=$ média dos postos na amostra combinada $(\mathrm{N}+1) / 2 ; R_{\mathrm{j}}=$ soma dos postos na j-ésima amostra ou grupo.

\subsection{Etapas de Desenvolvimento do Trabalho}

O trabalho foi desenvolvido em três etapas: definição do instrumento; coleta e preparação dos dados; e análise dos dados. Cada uma delas é descrita a seguir.

\subsection{Definição do instrumento}

Utilizou-se na pesquisa um questionário estruturado com 28 afirmações que consideram aspectos afetivos e cognitivos em relação à Estatística. Tratase da tradução e adaptação do questionário SATS - Survey of Attitudes Toward Statistics, (SCHAU, 1999).

A escala utilizada no questionário é do tipo Likert de cinco pontos, variando de " 1 - discordo totalmente" a " 5 - concordo totalmente". Essa escala mensura o nível de concordância do sujeito em relação a cada afirmação.

A escala original aborda, através de respostas autoavaliativas, quatro dimensões atitudinais: afeto, competência cognitiva, valor e dificuldade. A dimensão afeto trata de sentimentos positivos e negativos no que se refere à 
Estatística e é composta por seis afirmações que revelam questões afetivas. A dimensão competência cognitiva trata das atitudes a respeito dos conhecimentos intelectuais e habilidades que são demandados pela Estatística, sendo composta por seis afirmações. A terceira dimensão, valor, trata das atitudes quanto à utilidade, relevância e valor da Estatística no contexto profissional e pessoal. Esta terceira dimensão é composta por nove afirmações. A quarta dimensão, dificuldade, trata das atitudes diante da complexidade inerente ao assunto Estatística e é composta por sete afirmações. As afirmações serão expostas nas análises do trabalho e o questionário traduzido encontra-se em anexo.

De forma geral, as frases compreendem assuntos como: competência em lidar com problemas estatísticos e cálculos; atitudes em relação à matemática; intenção em aprender estatística; crenças em relação à utilidade da estatística e expectativas em relação ao uso da estatística na carreira.

$\mathrm{O}$ instrumento possui frases no sentido positivo e negativo. As frases positivas apresentam um assunto a favor da estatística. Em oposição, as frases negativas apresentam um assunto contra a estatística. Espera-se que os alunos que possuam atitudes favoráveis em relação a um assunto atribuam concordância às afirmações positivas. Analogamente, espera-se que os sujeitos que possuam atitudes desfavoráveis em relação ao assunto concordem com as afirmações que expressam algo negativo em relação a ele. Após a realização da tabulação, as variáveis com sentido negativo tiveram seus escores invertidos para que as análises pudessem ser realizadas.

\subsubsection{Coleta e preparação dos dados}

A amostragem não-probabilística foi realizada por conveniência, isto é, participaram voluntariamente da pesquisa os alunos presentes na sala de aula no momento da coleta dos dados.

Os dados foram coletados em agosto de 2005, e foram obtidos 337 questionários válidos, respondidos por alunos dos cursos de graduação em Administração da FEA-RP/USP, Mestrado em Administração de Organizações da FEA-RP/USP, alunos do curso de graduação em Ciências Contábeis da FEA-RP/USP e por alunos do curso de graduação em Administração de uma faculdade municipal localizada na região de Ribeirão Preto, denominada Faculdade $\mathrm{M}$ neste trabalho. 


\section{Análise dos Dados}

A análise dos dados foi feita em três etapas. Inicialmente, aplicou-se a análise fatorial de componentes principais com o objetivo de reduzir os dados em fatores. A seguir, aplicou-se a análise de cluster com intuito de encontrar grupos de alunos com atitudes semelhantes nas dimensões atitudinais extraídas na análise fatorial. Por fim, foram aplicados testes de hipóteses nãoparamétricos para verificar a existência de diferenças atitudinais significativas entre os grupos.

Utilizou-se o software SPSS 11.0 (Statistical Package for Social Sciences) para a realização das análises.

\subsection{Visão Geral dos Dados Coletados}

Participaram do estudo alunos ingressantes em cursos de graduação nos anos de 1995, 1996, 1999, 2000, 2001, 2002, 2003 e 2004, correspondendo respectivamente a $0,3 \% ; 0,3 \% ; 1,2 \% ; 7,1 \% ; 13,1 \% ; 16,3 \%$; $37,1 \%$; e $24,1 \%$ da amostra. A idade média foi de 22,8 anos com desviopadrão de 4,65 anos, havendo predominância do sexo masculino (59,1\% dos alunos). A maioria é composta por alunos da FEA-RP/USP, conforme pode ser observado no Quadro 2.

\begin{tabular}{|l|c|c|}
\hline \multicolumn{1}{|c|}{ Curso } & FEARP & Faculdade M \\
\hline Graduação em Administração & 119 & 118 \\
\hline Mestrado em Administração & 26 & 0 \\
\hline Graduação em Contabilidade & 74 & 0 \\
\hline Total & 219 & 118 \\
\hline
\end{tabular}

Quadro 2: Composição da amostra por curso (número de alunos).

Fonte: Elaborado pelos autores.

\subsection{Aplicação do Método dos Componentes Principais}

Inicialmente, aplicou-se aos dados à análise fatorial de componentes principais com objetivo de reduzir o número elevado de variáveis em algu- 
mas dimensões. Utilizou-se a rotação ortogonal de fatores Varimax, com objetivo de evitar que os fatores obtidos fossem correlacionados, o que prejudicaria a análise de cluster. Como resultado, obteve-se 0,908 como índice de Kaiser-Meyer-Olkin (KMO), ou seja, o modelo aplicado pode ser considerado adequado. A porcentagem de variação explicada foi de 52,721\%. Foram obtidos quatro fatores, compostos por dez variáveis no Fator 1, 12 variáveis no Fator 2, duas variáveis no Fator 3 e quatro variáveis no Fator 4 (Quadro 3).

\begin{tabular}{|c|c|c|c|}
\hline Fator 1 & Fator 2 & Fator 3 & Fator 4 \\
\hline $\begin{array}{l}\text { 5) vale a pena estudar } \\
\text { estatística } \\
\text { 7) a estatística deveria } \\
\text { ser uma competência } \\
\text { exigida para os profissi- } \\
\text { onais da minha área } \\
\text { 8) saber estatística me } \\
\text { tornará um profissional } \\
\text { diferenciado } \\
\text { 10) acho que a estatística } \\
\text { não é realmente útil na } \\
\text { maioria das profissões } \\
\text { 12) a estatística não tem } \\
\text { nenhuma utilidade fora } \\
\text { do meu trabalho } \\
\text { 13) uso estatística na } \\
\text { minha vida cotidiana } \\
\text { 15) acho legal ter } \\
\text { disciplinas de estatística } \\
\text { na grade curricular } \\
\text { 16) as conclusões } \\
\text { obtidas através da } \\
\text { estatística raramente são } \\
\text { utilizadas na vida } \\
\text { cotidiana } \\
\text { 19) não vou aplicar } \\
\text { estatística na minha } \\
\text { profissão } \\
\text { 25) a estatística é } \\
\text { irrelevante na minha } \\
\text { vida }\end{array}$ & $\begin{array}{l}\text { 2) me sinto inseguro } \\
\text { quando estudo estatística } \\
\text { 3) tenho dificuldades em } \\
\text { entender estatística por } \\
\text { causa da minha maneira de } \\
\text { raciocinar } \\
\text { 6) acho estatística uma } \\
\text { matéria muito complicada } \\
\text { 9) não entendo estatística } \\
\text { 11) fico frustrado com } \\
\text { meus resultados nas provas } \\
\text { de estatística } \\
\text { 14) fico tenso durante as } \\
\text { aulas de estatística } \\
\text { 20) cometo erros de } \\
\text { matemática quando faço } \\
\text { cálculos de estatística } \\
\text { 21) a estatística me assusta } \\
\text { 23) acho que consigo } \\
\text { aprender estatística } \\
\text { 24) entendo o que as } \\
\text { equações estatísticas } \\
\text { querem dizer } \\
\text { 27) tenho dificuldades em } \\
\text { entender os conceitos } \\
\text { estatísticos } \\
\text { 28) a maioria das pessoas } \\
\text { precisa aprender uma nova } \\
\text { maneira de raciocinar para } \\
\text { conseguir aprender } \\
\text { estatística }\end{array}$ & $\begin{array}{l}\text { 1) eu gosto de } \\
\text { estatística } \\
\text { 4) é fácil } \\
\text { entender as } \\
\text { fórmulas } \\
\text { estatísticas }\end{array}$ & $\begin{array}{l}\text { 17) a estatística é } \\
\text { aprendida } \\
\text { rapidamente pela } \\
\text { maioria das } \\
\text { pessoas } \\
\text { 18) para aprender } \\
\text { estatística é } \\
\text { necessário ter } \\
\text { muita disciplina } \\
\text { de estudo } \\
22) \text { a estatística } \\
\text { necessita de } \\
\text { grande uso de } \\
\text { computadores } \\
\text { 26) estatística é } \\
\text { uma disciplina } \\
\text { muito técnica }\end{array}$ \\
\hline
\end{tabular}

Quadro 3: Composição dos fatores.

Fonte: Elaborado pelos autores. 
A consistência interna do instrumento foi avaliada utilizando o coeficiente Alpha de Cronbach, para cada um dos quatro fatores (Quadro 4).

\begin{tabular}{|l|c|c|}
\hline \multicolumn{1}{|c|}{ Fator } & Coeficiente Alpha de Cronbach & Resultado \\
\hline 1 & 0,8695 & Satisfatório \\
\hline 2 & 0,8601 & Satisfatório \\
\hline 3 & 0,5289 & Insatisfatório \\
\hline 4 & 0,4767 & Insatisfatório \\
\hline
\end{tabular}

Quadro 4: Coeficientes de confiabilidade dos fatores obtidos.

Fonte: Elaborado pelos autores.

Com base nos coeficientes Alpha de Cronbach obtidos, optou-se por continuar a análise considerando apenas o Fator 1 (atitude sobre relevância da estatística na vida pessoal e profissional) e o Fator 2 (sentimentos e atitudes em relação aos conhecimentos necessários em estatística e à complexidade do assunto), com coeficientes Alpha indicativos de alta fidedignidade. Com base na escala SATS original, denominou-se os fatores respectivamente como valor (Fator 1) e competência cognitiva e dificuldade (Fator 2 ).

\subsection{Aplicação da Análise de Cluster}

A análise de cluster foi realizada sobre as variáveis Fator 1 e Fator 2 (média aritmética das notas que cada aluno atribuiu às variáveis agrupadas pela análise fatorial). Utilizou-se o método hierárquico com processo de agrupamento de Ward's e distância euclidiana como medida de distância.

Foram obtidos como resultado quatro clusters, sendo que $38 \%$ dos casos foram agrupados no cluster $1 ; 19,9 \%$ no cluster $2 ; 14,5 \%$ no cluster 3 e 27,3\% no cluster 4, como expõe o Gráfico 1. 


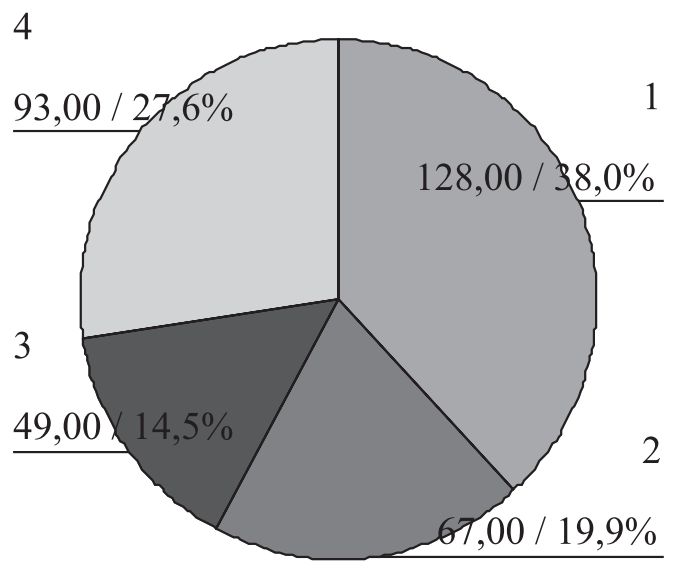

Gráfico 1: Frequência de casos nos clusters.

Fonte: Elaborado pelos autores.

Considerou-se como atitude favorável os itens que obtiveram escores "E" mais próximos de 5. Definiu-se: se $E<3,0$ a atitude é predominantemente negativa; se 3,0 $\leq E \leq 3,9$ a atitude é considerada conflitante ou indefinida; se $E \geq 4$ a atitude é considerada positiva.

Os clusters obtidos possuem os perfis descritos no Quadro 5.

\begin{tabular}{|l|l|l|l|l|c|}
\hline & Cluster $\mathbf{1}$ & Cluster 2 & Cluster $\mathbf{3}$ & Cluster 4 & Total \\
\hline Número de alunos & 128 alunos & 67 alunos & 49 alunos & 93 alunos & 337 \\
\hline Total FEA & 80 alunos & 49 alunos & 39 alunos & 51 alunos & 219 \\
\hline Total Faculdade M & 48 alunos & 18 alunos & 10 alunos & 42 alunos & 118 \\
\hline Administração - FEA & 53 alunos & 30 alunos & 19 alunos & 17 alunos & 119 \\
\hline Mestrado FEA & 3 aluno & 9 alunos & 10 alunos & 4 alunos & 26 \\
\hline Administração Faculdade M & 48 alunos & 18 alunos & 10 alunos & 42 alunos & 118 \\
\hline Contabilidade FEA & 24 alunos & 10 alunos & 10 alunos & 30 alunos & 74 \\
\hline Sexo Feminino & 46 mulheres & 34 mulheres & 16 mulheres & 42 mulheres & 138 \\
\hline Sexo Masculino & 82 homens & 33 homens & 33 homens & 51 homens & 199 \\
\hline Idade média & 22,28 anos & 23,31 anos & 22,82 anos & 23,14 anos & \\
\hline
\end{tabular}

Quadro 5: Estatísticas de frequência dos clusters.

Fonte: Elaborado pelos autores. 
Considerando a escala de interpretação atribuída anteriormente, podese concluir que:

a) Cluster 1: tem predomínio de alunos de graduação em Administração do sexo masculino $(64,1 \%)$ e a menor média etária dos quatro grupos (22,28 anos). As notas médias para ambos os fatores (Fator $1=3,8383$ e Fator $2=3,7630$ ) indica uma atitude conflitante. Portanto, o grupo não possui atitude fortemente definida quanto à relevância da Estatística na vida profissional e pessoal e quanto à dificuldade de aprendizagem da disciplina.

b) Cluster 2: é composto em sua maioria por alunos da FEA dos cursos de graduação em Administração e mestrado, sendo praticamente a metade dos alunos do sexo feminino. A nota média para o Fator $1=4,2493$ indica atitude positiva em relação ao primeiro fator, enquanto que a nota média para o Fator $2=3,1206$ indica atitude conflitante em relação ao segundo fator. Portanto, o grupo considera a estatística relevante no âmbito pessoal e profissional. No entanto, os alunos mostram-se receosos quanto à dificuldade de aprendizagem da disciplina. Ressalta-se que este é o cluster com maior média etária, seguido pelo cluster 4 , isso se deve provavelmente à presença dos alunos de mestrado, com faixa etária superior à dos alunos de graduação.

c) Cluster 3: há grande predomínio de alunos da FEA, sendo a maioria do sexo masculino. As notas médias para ambos os fatores (Fator $1=4,5939$ e Fator $2=4,2755$ ) indicam que os alunos apresentam atitudes favoráveis em relação à estatística. Este grupo considera a Estatística relevante no âmbito profissional e pessoal e julga adequada a carga de conhecimentos necessária para a aprendizagem dos conceitos, isto é, o grupo não considera que a disciplina possui uma dificuldade proibitiva.

d) Cluster 4: possui predomínio de alunos de graduação em Administração da faculdade $\mathrm{M}$ e graduação em Contabilidade da FEA$\mathrm{RP}$, sendo a maioria do sexo masculino. A nota média para o Fator $1=3,3118$ indica atitude conflitante e indefinida em relação a esse fator e a nota média para o Fator $2=2,6935$ indica atitude 
desfavorável em relação ao segundo fator. O grupo mostra incerteza quanto à relevância da Estatística e indica certo grau de medo em relação às exigências de conhecimento para aprendizagem da disciplina.

O Quadro 6 apresenta um resumo dos valores máximo, mínimo, média, desvio-padrão e coeficiente de variação das notas atribuídas para os clusters em cada fator.

\begin{tabular}{|l|l|l|l|l|l|l|l|l|l|l|}
\hline \multicolumn{3}{|c|}{ Fator 1 } & \multicolumn{3}{c|}{ Fator 2} \\
\hline & Mínimo & Máximo & Média & $\begin{array}{l}\text { Desvio- } \\
\text { padrão }\end{array}$ & $\begin{array}{l}\text { coef. } \\
\text { variação }\end{array}$ & Mínimo & Máximo & Média & $\begin{array}{l}\text { Desvio- } \\
\text { padrão }\end{array}$ & $\begin{array}{l}\text { coef. } \\
\text { variação }\end{array}$ \\
\hline Cluster 1 & 2,5 & 4,5 & 3,838 & 0,441 & $11,5 \%$ & 3,33 & 4,25 & 3,763 & 0,2185 & $6 \%$ \\
\hline Cluster 2 & 3,7 & 5 & 4,249 & 0,351 & $8 \%$ & 2,58 & 3,58 & 3,121 & 0,2153 & $7 \%$ \\
\hline Cluster 3 & 3,9 & 5 & 4,594 & 0,276 & $6 \%$ & 3,75 & 5 & 4,275 & 0,2828 & $7 \%$ \\
\hline Cluster 4 & 1 & 4,3 & 3,312 & 0,593 & $18 \%$ & 1,75 & 3,42 & 2,693 & 0,3972 & $15 \%$ \\
\hline
\end{tabular}

Quadro 6: Estatísticas descritivas dos clusters.

Fonte: Elaborado pelos autores.

\subsection{Aplicação dos Testes de Hipóteses}

Subsequentemente à aplicação da análise fatorial e da análise de cluster, onde se identificou as dimensões do estudo e grupos de alunos com atitudes semelhantes, julgou-se relevante avaliar a existência de diferença significativa de atitudes entre os clusters e entre os gêneros, bem como entre os cursos estudados.

Os Gráficos 2 e 3 indicam o posicionamento de cada cluster com relação aos escores obtidos para os Fatores 1 e 2. 


\section{Gráfico 2 - Escores dos conglomerados}

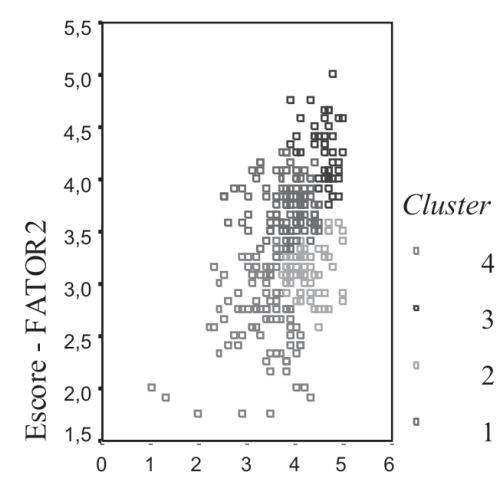

Escore - FATOR1

\section{Gráfico 3 - Box-plot atitude} dos grupos em relação aos fatores

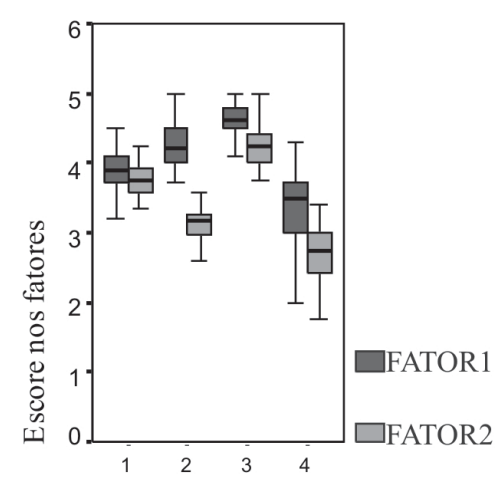

Clusters

Figura 2: Escores dos conglomerados e atitudes dos grupos em relação aos fatores.

Fonte: Elaborado pelos autores.

Observa-se, a partir dos Gráficos 2 e 3, que os clusters possuem atitudes diferentes. O grupo 3 apresenta atitude mais favorável em ambos os fatores e o grupo 4 apresenta atitude menos favorável. O box-plot sugere escores mais elevados em todos os clusters para o Fator 1.

Para verificar se essas diferenças observadas nos gráficos são significativas, foram aplicados testes de hipóteses não-paramétricos Kruskal-Wallis e Mann-Whitney.

O teste Kruskal-Wallis para k-amostras independentes foi aplicado com intuito de verificar a existência de diferença significativa entre os clusters em cada fator. As hipóteses para o teste são:

$H_{0}: \theta_{1}=\theta_{2}=\theta_{3}$ (as medianas das populações são iguais), atitudes dos clusters são iguais

$H_{1}$ : pelo menos um par de grupos possui medianas diferentes, atitude de pelo menos um par de clusters é diferente

Os resultados, ao nível de significância $\alpha=5 \%$, são ilustrados no Quadro 7. 


\begin{tabular}{|l|l|l|}
\hline \multicolumn{1}{|c|}{ Dimensão } & p-valor & Decisão \\
\hline Fator 1 & 0,000 & Rejeita-se \\
\hline Fator 2 & 0,000 & Rejeita-se \\
\hline
\end{tabular}

Quadro 7: Resultados do Teste Kruskal-Wallis para os clusters. Fonte: Elaborado pelos autores.

Observa-se que a hipótese nula foi rejeitada para ambos os fatores. Em nível de significância de 5\% existe diferença significativa de atitudes entre pelo menos um par de clusters para ambos os fatores do estudo. Dessa forma, aplicou-se o teste Mann-Whitney (duas amostras independentes) para verificar em quais grupos as diferenças de atitudes são significativas. As hipóteses genéricas para os testes são ("a" e "b" indicam o nome do grupo, por exemplo, em um teste entre Cluster 1 e Cluster 2 , $a=1$ e $b=2$ ):

$H_{0}: \theta_{\mathrm{a}}=\theta_{\mathrm{b}}$ (atitudes do grupo " $a$ " é igual a atitude do grupo " $b$ ")

$H_{1}: \theta_{\mathrm{a}} \neq \theta_{\mathrm{b}}$ (atitudes do grupo " $a$ " é diferente da atitude do grupo " $b$ ")

Os resultados são expostos no Quadro 8 (em nível de significância $\alpha=5 \%$ ).

\begin{tabular}{|c|c|c|c|c|}
\hline \multirow{2}{*}{ Teste } & \multicolumn{2}{|c|}{ Fator 1} & \multicolumn{2}{c|}{ Fator 2} \\
\cline { 2 - 5 } & p-valor & Decisão & p-valor & Decisão \\
\hline Cluster $1 \times$ Cluster 2 & 0,000 & Rejeita-se & 0,000 & Rejeita-se \\
\hline Cluster $1 \times$ Cluster 3 & 0,000 & Rejeita-se & 0,000 & Rejeita-se \\
\hline Cluster $1 \times$ Cluster 4 & 0,000 & Rejeita-se & 0,000 & Rejeita-se \\
\hline Cluster $2 \times$ Cluster 3 & 0,000 & Rejeita-se & 0,000 & Rejeita-se \\
\hline Cluster $2 \times$ Cluster 4 & 0,000 & Rejeita-se & 0,000 & Rejeita-se \\
\hline Cluster $4 \times$ Cluster 3 & 0,000 & Rejeita-se & 0,000 & Rejeita-se \\
\hline
\end{tabular}

Quadro 8: Resultados do Teste Mann-Whitney para os pares de clusters. Fonte: Elaborado pelos autores.

Observa-se, por meio do teste, que há diferença significativa de atitudes entre todos os pares de clusters para ambos os fatores. O Cluster 1 é caracterizado por possuir atitude conflitante em ambos os fatores, ou seja, os alunos não possuem atitude bem definida com respeito à relevância $e$ aplicabilidade da Estatística, tampouco quanto à sua capacidade de aprender Estatística. O Cluster 2 apresenta atitude positiva no primeiro fator, ou seja, considera a Estatística uma disciplina relevante e realmente útil no âm- 
bito pessoal e profissional. Em relação ao Fator 2, o Cluster 2 apresenta atitude conflitante. O Cluster 3 possui atitude positiva em ambos os fatores, indicando que os respondentes consideram a Estatística uma disciplina relevante e com grande aplicação. Os alunos não se sentem inseguros ao estudar esta disciplina e acreditam ser capazes de aprender os conceitos e ferramentas. Por fim, o Cluster 4 apresenta atitude conflitante no Fator 1, ou seja, os alunos possuem atitude bem definida quanto à relevância e utilidade da estatística. No que concerne ao Fator 2, o Cluster 4 apresenta e atitude negativa, indicando que os respondentes sentem insegurança ao estudar Estatística e não se consideram capazes de aprender os conceitos e as ferramentas.

Adicionalmente, julgou-se pertinente analisar separadamente o comportamento dos alunos de acordo com o curso ao qual pertencem, para que se conheça o perfil atitudinal dos diferentes cursos estudados. O Gráfico 4 expõe os escores de cada curso para cada fator.

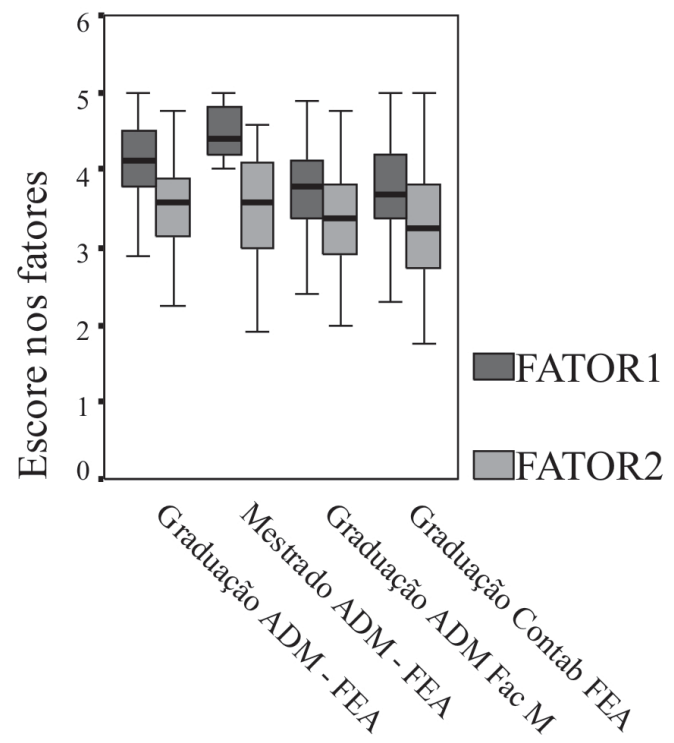

Gráfico 4: Box plot atitude dos cursos em relação aos fatores.

Fonte: Elaborado pelos autores.

O teste Kruskal-Wallis foi aplicado ao nível de significância, com as seguintes hipóteses: 
$H_{0}: \theta_{1}=\theta_{2}=\theta_{3}$ (as medianas das populações são iguais), atitudes dos cursos são iguais

$H_{1}$ : pelo menos um par de grupos possui medianas diferentes, atitude de pelo menos um par de cursos é diferente

O teste indicou diferença significativa de atitude em pelo menos um par de cursos em ambos os fatores, conforme expõe o Quadro 9.

\begin{tabular}{|l|l|l|}
\hline \multicolumn{1}{|c|}{ Dimensão } & p-valor & Decisão \\
\hline Fator 1 & 0,000 & Rejeita-se \\
\hline Fator 2 & 0,042 & Rejeita-se \\
\hline
\end{tabular}

Quadro 9: Resultados do teste Kruskal-Wallis para os cursos.

Fonte: Elaborado pelos autores.

Para verificar em quais pares de cursos existe diferença significativa, aplicou-se o teste Mann-Whitney dentro de cada cluster. As hipóteses para o teste são:

$H_{0}: \theta_{\mathrm{a}}=\theta_{\mathrm{b}}$ (atitudes do curso " $a$ " é igual a atitude do curso " $b$ ")

$H_{1}: \theta_{\mathrm{a}} \neq \theta_{\mathrm{b}}$ (atitudes do curso " $a$ " é diferente da atitude do curso " $b$ ")

O Quadro 10 apresenta os resultados obtidos ao nível de significância $\alpha=5 \%$.

\begin{tabular}{|l|c|c|c|c|}
\hline \multirow{2}{*}{ Teste } & \multicolumn{2}{c|}{ Fator 1 - Valor } & \multicolumn{2}{c|}{$\begin{array}{c}\text { Fator 2 - Competência } \\
\text { cognitiva e dificuldade }\end{array}$} \\
\cline { 2 - 5 } & p-valor & Decisão & p-valor & Decisão \\
\hline Graduação ADM FEA-RP x Mestrado FEA-RP & 0,000 & Rejeita-se & 0,836 & Não se rejeita \\
\hline Graduação ADM FEA-RP x Graduação ADM Fac. M & 0,000 & Rejeita-se & 0,058 & Não se rejeita \\
\hline $\begin{array}{l}\text { Graduação ADM FEA-RP x Graduação Contabilidade } \\
\text { FEA-RP }\end{array}$ & 0,000 & Rejeita-se & 0,008 & Rejeita-se \\
\hline Mestrado FEA-RP x Graduação ADM Fac. M & & & 0,319 & Não se rejeita \\
\hline Mestrado FEA-RP x Graduação Contabilidade FEA-RP & 0,000 & Rejeita-se & 0,133 & Não se rejeita \\
\hline Contabilidade FEA-RP x Graduação ADM Fac. M & 0,8335 & Não se rejeita & 0,293 & Não se rejeita \\
\hline
\end{tabular}

Quadro 10: Resultados dos testes de significância entre os cursos.

Fonte: Elaborado pelos autores. 
Conforme exposto no Quadro 10, as diferenças ocorrem principalmente no Fator 1, indicando uma diferença significativa quanto à percepção da relevância e utilidade da Estatística entre os cursos. O Quadro 11 ilustra a atitude de cada um dos cursos para os fatores.

\begin{tabular}{|l|c|c|}
\hline \multicolumn{1}{|c|}{ Curso } & Fator 1 - valor & $\begin{array}{c}\text { Fator 2 - competência } \\
\text { cognitiva e dificuldade }\end{array}$ \\
\hline Graduação ADM FEA-RP & Positiva & Conflitante tendendo a positiva \\
\hline Mestrado FEA-RP & Positiva & Conflitante \\
\hline Graduação ADM Fac. M & Conflitante & Conflitante \\
\hline Graduação Contabilidade FEA-RP & Conflitante & Conflitante tendendo a negativa \\
\hline
\end{tabular}

Quadro 11: Atitudes dos cursos em cada fator.

Fonte: Elaborado pelos autores.

Os cursos de mestrado e de graduação em Administração da FEA-RP apresentam atitude positiva em relação ao Fator 1. Entretanto, os alunos do mestrado apresentam a atitude mais positiva em relação a esse fator, considerando a Estatística como uma disciplina realmente relevante, com empregabilidade no âmbito profissional e pessoal. Tais resultados se opõem às considerações tecidas no estudo de Carzola et al. (1999), quando afirmam que para os alunos de pós-graduação a estatística é uma disciplina necessária, devido a uma provável utilização na dissertação e essa necessidade pode gerar ansiedade e atitudes mais negativas. Neste estudo observou-se que a necessidade eminente da utilização da estatística nas dissertações levou os alunos pesquisados a apresentarem atitudes positivas com relação à relevância desta. Contudo, a atitude em relação à dificuldade da estatística apresentou-se conflitante.

Em geral, ao que concerne ao Fator 2, observou-se atitude conflitante, com diferença significativa apenas entre o curso de graduação em Administração da FEA-RP e o curso de graduação em Contabilidade da FEA-RP. Apesar de ambos os cursos apresentarem atitudes conflitantes, a atitude dos alunos de Administração é mais favorável do que a dos alunos de Contabilidade. Isso indica que os alunos do curso de graduação em Administração da FEA-RP possuem maior autoconfiança em relação à sua capacidade de aprender Estatística e sentem-se mais seguros ao estudar esta disciplina.

Realizou-se também o teste Mann-Whitney para verificar a existência de diferença significativa de atitudes entre os sexos. Ao nível de significância 
de $5 \%$ observou-se diferença significativa de atitudes apenas para o Fator 2 , que trata dos aspectos afetivos. Não houve diferença significativa quanto ao Fator 1, ou seja, ambos os sexos consideram a estatística um assunto relevante. Em geral, embora ambos os sexos apresentem atitude conflitante em relação aos dois fatores, para o Fator 2, o sexo masculino apresenta atitude mais positiva do que o sexo feminino, corroborando com o estudo de Silva, Carzola e Brito (1999).

\section{Conclusões}

O estudo atingiu os objetivos propostos, trazendo novos insights sobre as atitudes dos alunos do curso de Administração e Contabilidade quanto à disciplina de Estatística.

Duas dimensões atitudinais em relação à Estatística foram obtidas por meio da análise fatorial de componentes principais. Cada uma das dimensões identificadas tratou de um aspecto distinto da Estatística. A Dimensão 1, denominada valor, tratou da relevância e utilidade percebida da Estatística. A Dimensão 2, denominada competência cognitiva e dificuldade, tratou da percepção de dificuldade quanto à Estatística e dos conhecimentos e habilidades necessários para a aprendizagem dos conteúdos estatísticos. Aplicouse, com base nas dimensões encontradas, a análise de cluster, com intuito de encontrar grupos com atitudes semelhantes no que concerne aos fatores. A aplicação dessa ferramenta resultou na formação de quatro grupos, um com atitude predominantemente negativa, um com atitude predominantemente positiva e dois com atitudes conflitantes.

Com base nos testes de hipóteses aplicados constatou-se que, em geral, os alunos possuem sentimentos positivos em relação à Estatística. Julgam-na uma disciplina relevante e possuem consciência da utilidade dos conhecimentos estatísticos, tanto na vida profissional quanto pessoal. Em oposição, apresentam atitudes conflitantes com tendência negativa na dimensão competência cognitiva e dificuldade. Os resultados revelaram, ainda, que os alunos consideram a Estatística uma disciplina complexa, com a qual costumam apresentar dificuldades de aprendizagem. Os testes aplicados mostraram diferenças significativas de atitudes em ambos os fatores, para todos os clusters. No que concerne aos cursos, observou-se diferença de atitudes em cinco pares de cursos na Dimensão 1 (valor) e para apenas um par de cursos 
na Dimensão 2 (competência cognitiva e dificuldade). De forma geral, percebe-se que o curso de Mestrado da FEA-RP possui atitude mais positiva em relação ao valor da Estatística. Os alunos do mestrado atribuíram escores mais elevados nesta dimensão, ou seja, eles consideram a Estatística uma disciplina realmente relevante e de grande aplicabilidade. Na dimensão competência cognitiva e dificuldade, a atitude é, em geral, conflitante. Entretanto, a atitude dos alunos do curso de Contabilidade da FEA-RP possui tendência mais negativa, indicando que os alunos sentem maior tensão ao estudar a disciplina, possuem insegurança quanto à aprendizagem dos conceitos e ferramentas e sua percepção de dificuldade é maior.

Nesse contexto, algumas reflexões são necessárias, tendo em vista que pode ser considerado um grande progresso o fato de os alunos perceberem a Estatística como relevante e entenderem sua empregabilidade fora do ambiente acadêmico. Contudo, observou-se que os alunos ainda consideram a Estatística como uma disciplina complexa e costumam apresentar dificuldade de aprendizagem. $\mathrm{O}$ medo associado à dificuldade de aprendizagem conduz a uma atitude negativa que, por sua vez, pode levar a real dificuldade de aprendizagem, prejudicando a formação do aluno.

Considerando que, em geral, a disposição para aprendizagem se mostra positiva, deve-se localizar esforços no intuito de romper antigos paradigmas em relação à Estatística, favorecendo, assim, um processo de aprendizagem efetiva.

O objetivo de inserir disciplinas de Estatística nos cursos é desenvolver nos estudantes habilidades flexíveis e críticas de solução de problemas e análise de dados. No entanto, para que esse objetivo seja alcançado, as disciplinas de Estatística ministradas nos diferentes cursos precisam de reformulação e flexibilização, estando mais voltadas para a aplicação dos conhecimentos estatísticos e não à dedução de modelos e fórmulas. É necessária a criação de uma atmosfera que desenvolva o sentimento de autoconfiança e segurança para testar diferentes ferramentas, conforto para lidar com incertezas e probabilidades e motivação para trabalhar com problemas que podem requerer grandes investimentos de tempo e energia.

Como limitações do trabalho há a utilização da escala tipo Likert. Essa escala não permite o reconhecimento das causas para a atitude. Todavia, o perfil atitudinal traçado a partir da escala adotada permitiu constatar quais aspectos não estruturados (crenças e valores) influenciam as atitudes e, em educação, as atitudes podem determinar dificuldades de aprendizagem. Adi- 
cionalmente, é importante ressaltar que as conclusões obtidas consideram apenas os grupos analisados, não permitindo a generalização dos resultados para a toda população de estudantes das duas instituições de ensino.

\section{Attitudes of Applied Social Science Courses' Students Toward Statistics}

\section{Abstract}

The objective of this research was to identify the students' behavior from Management and Accounting Courses in respect to the subject Statistics. The student's profile was obtained by the use of issues, the SATS scale (Survey of Attitudes Toward Statistics), applied to 337 students from Management and Accounting Courses from 2 colleges. The research indicates 2 dimensions of attitude reached by factor analysis, denominated value and cognitive competence and difficulty. Cluster analysis was applied and found four groups of students, one of them has positive attitudes, one has negative attitudes and two don't have well defined attitudes. Mann-Whitney and Kruskal-Wallis were applied to verify the differences between the clusters attitudes, among the courses attitudes and between male and female attitudes. Students present positive behavior in connection to Statistics. However, there is an unfavorable behavior about the complexity of Statistics and their beliefs about learning statistical concepts and tools.

Key-words: Attitudes. Educational Evaluation. Applied Statistics.

\section{Referências}

BEM, D. J. Convicções, atitudes e assuntos humanos. São Paulo: Edusp, 1973.

BRESSAN, L. A. Atitudes frente ao trabalho interdisciplinar em equipes de saúde mental. 1995. Dissertação (Mestrado em Saúde Mental) Faculdade de Medicina de Ribeirão Preto, Universidade de São Paulo, Ribeirão Preto, 1995. 
CARZOLA, I. M.; SILVA, C. B.; VENDRAMINI, C.; BRITO, M. R. F. Adaptação $e$ validação de uma escala de atitudes em relação à estatística. In: Conferência Internacional "Experiências e Expectativas do Ensino de Estatística - Desafios para o Século XXI", 1999, Florianópolis. Anais... Florianópolis: Associação Internacional para Educação em Estatística, 1999. Disponível em: <http:// www.inf.ufsc.br/ cee/pasta1/art3.html>. Acesso em: 2 mar. 2007.

GAL, I.; GINSBURG, L. The role of beliefs and attitudes in learning statistics: toward an assessment framework. Journal of Statistics Education, v. 2, n. 2, 1994. Disponível em: < http://www.amstat.org/publications/jse/v2n2/ gal.html >. Acesso em: 25 set. 2005.

GAL, I.; GINSBURG, L.; SCHAU, C. Monitoring attitudes and beliefs in statistics education. In: GAL, 1.; GARFIELD, J.B. The assessment challenge in statistics education. Amsterdam: IOS Press, 1997. p.37-51. Disponível em: <http://www.stat.auckland.ac.nz/ iase/ publications>. Acesso em: 13 jun. 2005.

GELMAN, A. A course on teaching statistics at the university level. The American Statistician, v. 59, 1, p.4-8, fev. 2005.

GIL, A. C. Como elaborar projetos de pesquisa. 4. ed. São Paulo: Ed. Atlas, 2002, 175 p.

GONÇALVES, N. Atitudes dos alunos do curso de pedagogia com relação à disciplina de estatística no laboratório de informática. 2002. 191 f. Tese (Doutorado em Educação Matemática) - Faculdade de Educação, Universidade Estadual de Campinas, Campinas, 2002.

HAIR, J. F. Jr. et al. Multivariate data analysis. 5. ed. New Jersey: Prentice Hall, 1998.

NOLAN, D.; SPEED, T. P. Teaching statistics theory through applications. The American Statistician, v. 53, 4, p. 370-375, nov. 1999.

NORUSIS, M. J. SPSS 11.0: guide to data analysis. New Jersey: Prentice Hall, 2002.

PAN, W.; TANG, M. Examining the effectiveness of innovative instructional methods on reducing statistics anxiety for graduate students in social sciences. Journal of Instructional Psychology, Mobile, v. 31, n. 2, p. 149-159, 2004. 
PASQUALI, L. Psicometria: teoria e aplicações. Brasília: Editora Universidade de Brasília, 1997. 276 p.

PETOCZ, P.; REID, A. Something strange and useless: service students' conceptions of statistics, learning statistics and using statistics in their future profession. International Journal of Mathematical Education in Science and Technology, London, v. 36, n.7, p. 789-800, 2005.

PEDRÃO, L. J.; AVANCI, R. C. de; MALAGUTI, S. E. Perfil das atitudes de alunos do curso de enfermagem frente à doença mental, antes da influência da instrução acadêmica, proveniente de disciplinas de área específica. Rev. Latino Americana Enfermagem, v. 10, 6, p.794-799, nov./dez. 2002.

REIS, E. Estatística Multivariada Aplicada. 2. ed. Lisboa: Edições Sílabo, 2001. 343 p.

SCHAU, C. SATS: Survey of Attitudes Toward Statistics. 1999. Disponível em: <http://www.unm.edu/ cschau/satshomepage.htm>. Acesso em: 5 mar. 2005.

SIEGEL, S. Estatística não-paramétrica para ciências do comportamento. São Paulo: McGraw-Hill, 1975. 350 p.

SIEGEL, S.; CASTELLAN, N.J. Jr. Estatística não-paramétrica para ciências do comportamento. 2. ed. Porto Alegre: Artmed, 2006. 448 p.

SILVA, C. B.; BRITO, M. R. F.; CARZOLA, I. M.; VENDRAMINI, C. M. M. Atitudes em relação à estatística e à matemática. PsicoUSF, v. 7, n. 2, p.219228, jul/dez 2002.

SILVA, C. B.; CARZOLA, I. M.; BRITO, M. R. F. Concepções e atitudes em relação à estatística. In: Conferência Internacional "Experiências e Expectativas do Ensino de Estatística - Desafios para o Século XXI", 1999, Florianópolis.

Anais... Florianópolis: Associação Internacional para Educação em Estatística, 1999. Disponível em: <http://www.inf.ufsc.br/ cee/pasta1/art3.html>. Acesso em: 2 mar. 2007.

SUAPANG, P.; PETOCZ, P.; KALCEFF, W. Stundent attitudes to learning business statistics online vs tradicional methods. In: HIGHER EDUCATION RESEARCH AND DEVELOPMENT OF AUSTRALASIA ANNUAL CONFERENCE, 26., 2003, Christchurch. Anais... Christchurch: Higher Education Research and Development of Australasia, 2003. Disponível em: <http://www.herdsa.org.au/conferences.php>. Acesso em: 23 mai. 2006. 
TRONCON, L. E. A. de; et al. Atitudes de graduandos em medicina em relação a aspectos relevantes da prática médica. Revista Brasileira de Educação

Médica, v. 27, n.1, jan./abr. 2003.

\section{Anexo A}

Questionário SATS traduzido.

\begin{tabular}{|c|c|c|c|c|c|c|}
\hline & & 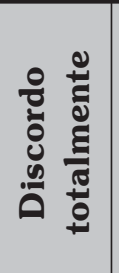 & 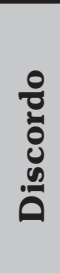 & 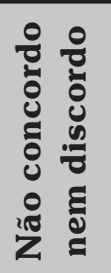 & 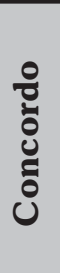 & 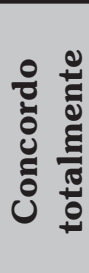 \\
\hline 1 & Eu gosto de estatística & 1 & 2 & 3 & 4 & 5 \\
\hline 2 & Sinto-me inseguro quando estudo estatística & 1 & 2 & 3 & 4 & 5 \\
\hline 3 & $\begin{array}{l}\text { Tenho dificuldades em entender estatística } \\
\text { por causa da minha maneira de raciocinar }\end{array}$ & 1 & 2 & 3 & 4 & 5 \\
\hline 4 & É fácil entender as fórmulas estatísticas & 1 & 2 & 3 & 4 & 5 \\
\hline 5 & Vale a pena estudar estatística & 1 & 2 & 3 & 4 & 5 \\
\hline 6 & $\begin{array}{l}\text { Acho a estatística uma matéria muito } \\
\text { complicada }\end{array}$ & 1 & 2 & 3 & 4 & 5 \\
\hline 7 & $\begin{array}{l}\text { A estatística deveria ser uma competência } \\
\text { exigida para os profissionais da minha área }\end{array}$ & 1 & 2 & 3 & 4 & 5 \\
\hline 8 & $\begin{array}{l}\text { Saber estatística me tornará um profissional } \\
\text { diferenciado }\end{array}$ & 1 & 2 & 3 & 4 & 5 \\
\hline 9 & Não entendo estatística & 1 & 2 & 3 & 4 & 5 \\
\hline 10 & $\begin{array}{l}\text { Acho que a estatística não é realmente útil } \\
\text { na maioria das profissões }\end{array}$ & 1 & 2 & 3 & 4 & 5 \\
\hline 11 & $\begin{array}{l}\text { Fico frustrado com meus resultados nas } \\
\text { provas de estatística }\end{array}$ & 1 & 2 & 3 & 4 & 5 \\
\hline 12 & $\begin{array}{l}\text { A estatística não tem nenhuma utilidade fora } \\
\text { do meu trabalho }\end{array}$ & 1 & 2 & 3 & 4 & 5 \\
\hline 13 & Uso estatística na minha vida cotidiana & 1 & 2 & 3 & 4 & 5 \\
\hline 14 & Fico tenso durante as aulas de estatística & 1 & 2 & 3 & 4 & 5 \\
\hline
\end{tabular}




\begin{tabular}{|c|c|c|c|c|c|c|}
\hline & & 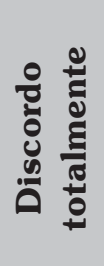 & $\begin{array}{l}\stackrel{0}{0} \\
\stackrel{0}{0} \\
\stackrel{0}{0}\end{array}$ & 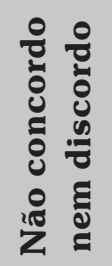 & $\begin{array}{l}\circ \\
\stackrel{0}{0} \\
\dot{0} \\
\tilde{0}\end{array}$ & 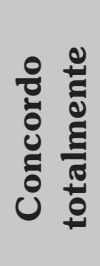 \\
\hline 15 & $\begin{array}{l}\text { Acho legal ter disciplinas de estatística na } \\
\text { grade curricular }\end{array}$ & 1 & 2 & 3 & 4 & 5 \\
\hline 16 & $\begin{array}{l}\text { As conclusões obtidas através da estatística } \\
\text { raramente são utilizadas na vida cotidiana }\end{array}$ & 1 & 2 & 3 & 4 & 5 \\
\hline 17 & $\begin{array}{l}\text { A estatística é aprendida rapidamente pela } \\
\text { maioria das pessoas }\end{array}$ & 1 & 2 & 3 & 4 & 5 \\
\hline 18 & $\begin{array}{l}\text { Para aprender estatística é necessário ter } \\
\text { muita disciplina de estudo }\end{array}$ & 1 & 2 & 3 & 4 & 5 \\
\hline 19 & Não vou aplicar estatística na minha profissão & 1 & 2 & 3 & 4 & 5 \\
\hline 20 & $\begin{array}{l}\text { Cometo erros de matemática quando faço } \\
\text { cálculos de estatística }\end{array}$ & 1 & 2 & 3 & 4 & 5 \\
\hline 21 & A estatística me assusta & 1 & 2 & 3 & 4 & 5 \\
\hline 22 & $\begin{array}{l}\text { A estatística necessita de grande uso de } \\
\text { computadores }\end{array}$ & 1 & 2 & 3 & 4 & 5 \\
\hline 23 & Acho que consigo aprender estatística & 1 & 2 & 3 & 4 & 5 \\
\hline 24 & $\begin{array}{l}\text { Entendo o que as equações estatísticas } \\
\text { querem dizer }\end{array}$ & 1 & 2 & 3 & 4 & 5 \\
\hline 25 & A estatística é irrelevante na minha vida & 1 & 2 & 3 & 4 & 5 \\
\hline 26 & Estatística é uma disciplina muito técnica & 1 & 2 & 3 & 4 & 5 \\
\hline 27 & $\begin{array}{l}\text { Tenho dificuldades em entender os conceitos } \\
\text { estatísticos }\end{array}$ & 1 & 2 & 3 & 4 & 5 \\
\hline 28 & $\begin{array}{l}\text { A maioria das pessoas precisa aprender uma } \\
\text { nova maneira de raciocinar para conseguir } \\
\text { aprender estatística }\end{array}$ & 1 & 2 & 3 & 4 & 5 \\
\hline
\end{tabular}

